\title{
Study on Multi-media Assistance in Higher Mathematics Teaching
}

\section{Linyuan Fan}

School of Statistics, Capital University of Economics and Business, Beijing 100070, China.

fanlinyuan@cueb.edu.cn

Keywords: Multi-media assistance; higher mathematics teaching; Advantages and disadvantages.

\begin{abstract}
In this paper, we discuss and study the advantages and disadvantages on multi-media assistance in higher mathematics teaching in different ways. Moreover, we propose some suggestions on improving teaching modes and methods with multi-media assistance.
\end{abstract}

\section{Introduction}

As information technology and Internet developing incredibly, traditional teaching mode such as 'blackboard and chalk' has been replaced by various kinds of teaching modes, one of which is multi-media assistance. Capital University of Economics and Business has been introducing multi-media assistance teaching for the past years. During teaching practice by author himself, multi-media assistance did help solve some difficult problems in traditional teaching modes. However, it also brought some other new problems [1-8]. In this paper, we discuss both advantages and disadvantages which multi-media assistance in higher mathematics teaching brought with. Moreover, we propose some suggestions on that so as to make multi-media assistance better.

\section{Advantages on Multi-media Assistance}

\subsection{Inspiring interest of students}

In class, multi-media assistance attracts senses of students by different kinds of pictures, sounds, movies, cartoons, and etc. which traditional teaching mode cannot bring out. And that will definitely inspire curiosity and feeling of freshness of students, which directly motivates their interest. For example, while introducing the definition 'bi-jection', we use a 3D-graphic motion showing that how a pole projection is defined, also expressing how a world map is made to show the Earth. That is nothing but a practical example of a 'bi-jection' in our normal life. In this way, students may understand the definition more quickly and precisely.

\subsection{Showing the Process of Knowledge developing}

In front of students, books always show science and knowledge systematically. In most cases books omit the process how that very knowledge came out and how it was developed step by step. Traditional teaching ways cannot overcome the disadvantage since only static pictures could be used. However, multi-media offer us a chance. When introducing the definition 'limit', how to show that number series are approaching the limit more and more closely. With animation, teachers are able to show that process directly and visually, which help students experience how 'limit' is made and defined.

\subsection{Improving efficiency on courses}

Multi-media uses 'electronic teaching plans' instead of traditional handwriting teaching plans. By preparing all needed definition, theorems, examples, notices, and etc. in advance, teachers are able to save time in handwriting on the blackboard, increase contents such as mathematics history, application, and etc. in class. Although teachers should pay more time on preparing, students may get more knowledge at the same period of time, which improves efficiency enormously.

\subsection{Helping prominent keynotes and difficulties}

With multi-media assistance, teachers are able to prominent keynotes in visual ways, such as important definitions, theorems, key points, key geometric graphics, and etc. In the meantime, difficulties can be prominent and broken through. On one hand, multi-media turn static knowledge 
into dynamic, continuous process, helping students understand more easily. On the other hand, multi-media overcome some difficulties that cannot be omitted by handwriting. For example, when introducing the definition 'Integral', no matter how thin teachers draw the divided interval with chalk on the blackboard, the process dividing the interval into infinite parts cannot be shown. But with multi-media, dynamic animation is able to show that process visually and precisely.

\section{Disadvantages and Problems on Multi-media assistance}

As mentioned above, multi-media assistance bring vitality and convenience into teaching mode, however, by lack of reforming on teaching methods, teaching contents, learning methods and etc., it has brought some disadvantages and new problems inevitably.

\subsection{Courseware Type is Single}

At present most teachers use courseware made by 'PowerPoint'. The type of courseware is single, which is one-way demonstration. Other types like discussing type, experiment type, solving problems type and etc. are rare. On one hand, teachers have not changed their traditional teaching methods but replacing chalk and blackboard with electronic instruments. On the other hand, teachers should improve their own teaching techniques by learning more mathematical software (Mathematica, Matlab, Flash, etc.). Each software has its special function, so how to choose proper software is also important.

\subsection{Hard to Control Teaching Paces}

In traditional teaching mode, teachers write on the blackboard while explaining. Both students and teachers are almost at the same pace. However, with multi-media and computer demonstration, all contents are shown at the same time, with teachers explaining, students cannot make notes even without thinking at some time. If that happened more often, it will make students passive to accept knowledge instead of activating their own thinking ability. Moreover, teachers usually explain much faster with multi-media than in the traditional teaching mode, which is easy to strain students. That reduces the efficiency enormously.

\subsection{Lack of Interaction}

Class is interaction between teachers and students. Modern teacher methods emphasize on centering on students but not teachers, motivating their own activities. While in most class, teachers demonstrate all prepared courseware, data, knowledge for students, who are passive to accept all those. Teachers usually focus on the demonstration but omitting interaction with students, how the class is going on, whether students understand what they just said. If that happened too often, students would feel like they were just robots or idiots in class.

\subsection{Emphasizing on Courseware Forms Excessively}

Multi-media courseware includes text, pictures, animations, which brings dynamic effects, helping visualize the static and abstract knowledge. However, some courseware is made excessively gaudily. Too much gaudy pictures, music and other unrelated information is inserted. That draws students' attentions from thinking on their own, which leads to reduction of efficiency of the class.

\section{Suggestions on Multi-media Assistance in Teaching Higher Mathematics}

\subsection{Improve Teaching Methods}

No matter how advanced multi-media is, it can be used as a tool in teaching. The key point to reform the teaching is to improve teaching methods. Modern teaching methods include not only the assistance of multi-media, but also modern teaching contents, teaching managements and etc. Therefore, we should focus on the purpose that helping improve students understanding knowledge, study mathematical theory, solving practical problems by applying modern multi-media assistance. Without change of teaching methods, multi-media is nothing but an advanced blackboard.

\subsection{Improve Practicability and Variety of Courseware}

A good courseware should be organized properly, not gaudily just for attracting students' attention, also emphasize on the contents. Appropriate amount of contents should be carefully chosen. 
Moreover, teachers should prominent the keynotes and difficulties remarkably in order to motivate the students' interest and their own activity. Meanwhile, different kinds of courseware can also inspire students' interest to study, to discover new theory.

\subsection{Combine Traditional Teaching Mode with Multi-media Assistance}

During class, teachers should realize that multi-media is just an assistance for teaching itself. Multi-media does have its convenience but also some limit. For example, deduction is the most important part in higher mathematics teaching. And the most effective way to explain how the deduction is done one step by one step is to write it down on the blackboard. Therefore, blackboard should not be abandoned. Meanwhile, teachers should not waste time repeat writing the theorem or definition again on the blackboard since it is in everyone's textbook. At that time, multi-media is able to play an important role. Therefore, teachers should combine traditional teaching mode with multi-media assistance teaching mode, which would give students more time and space to think, study and discover the uncertain, unknown world.

\section{Summary}

Through recent research and practice, we realize that it is our goal to train students' mathematical quality, improve their ability to solve practical problems, inspire their interest to learn. With multi-media assistance, we can turn abstract mathematics into lively, dynamic state, also it brings out some problems. However, we believe that, through practice, discussion and study, we will make higher mathematics teaching better and better.

\section{Acknowledgement}

The author would like to thank all the editors.

Research was supported by Teaching Reforming Funding 'Study on Reform of Course-Higher Mathematics’ granted by Capital University of Economics and Business 2017.

\section{References}

[1]. Hongliang Dai. Practice and Understanding on Reforming Teaching Higher Mathematics with Multi-media. Studies in College Mathematics. Vol. 9 (2006) No. 6, p. 54-56.

[2]. Meilan Deng. Thinking on Cases Teaching Methods of Higher Mathematics in Economics Colleges. College Forum. Vol.9 (2011), p. 69.

[3]. Dongmei Fan, Jian Wu. Studies on Teaching Reforming of Higher Mathematics in Economics Majors. Journal of Hubei University of Economics (Humanities and Social Sciences). Vol. 12(2015) No.7, p.195-196.

[4]. Hua Li. Studies on Teaching Reforming of Higher Mathematics in Economics Majors. China Adults Education. Vol. 17(2009), p. 126-127.

[5]. Jinxia Liu, Juan Chen, Shuqin Zhao. The Reform of Content of the Couse Higher Mathematics for Economics and Management Majors. Journal of Jimei University. Vol. 8(2007) No.4, p. 89-92.

[6]. LAN Min, Xiaomin Chen. Several Ideas about the Teaching Reform of the Course Higher Mathematics. Journal of Southwest China Normal University (Nature Science Edition). Vol. 37(2012) No. 2, p.139-141.

[7]. Mengqiu Wu, Weihua Zheng, Ping Shi, Dapeng Feng. Investigation and Analysis on Advantages and Disadvantages of Multi-media Teaching in Higher Mathematics. Higher Science Education. Vol. 5(2009), p.33-36

[8]. Zongjian Zheng, Liu Liu, Binru Zhang. On the Reform of Mathematics Teaching Complemented with Mathematical and Modeling Experiments. Sichuan University of Arts and Science Journal. Vol. 22(2012) No.2, p.146-149. 